\title{
USE OF LOCKING COMPRESSION PLATES FOR DEFORMITY CORRECTION OF THE FOREARM BONES IN CHILDREN
}

\author{
Jiri Jochymek*, Jan Skvaril, David Stary, Petr Gal, Ladislav Planka
}

\begin{abstract}
Department of Pediatric Surgery, Orthopedics, and Traumatology (DPSOT) of the Children's Medical Center (CMC), Faculty Hospital in Brno, and Medical Faculty of the Masaryk University in Brno, Czech Republic e-mail:jochymek@fnbrno.cz
\end{abstract}

Received: November 11, 2008; Accepted: January 5, 2009

Key words: Locking compression plates (LCP)/Osteosynthesis/Distal forearm/Deformity

The aim of the study: The aim of our study was to assess treatment results of angular deformities in distal radius by a system of the locking compression plates (LCP) at our clinic.

Methods: Our source data was collected prospectively from the records of patients where the locking compression plate was used for angulation correction of distal forearm between 2006 and 2007. The patients were divided by sex, the age range was defined and two groups were formed based on the initial diagnosis: the group of posttraumatic deformities ( 2 patients; $29 \%$ ) and the group of no traumatic deformities ( 3 patients with congenital shortening of ulna, valgus deformity and overgrowth of radius and 2 patients with exostoses multiplices with shortening of ulna and overgrowth of radius with ulnar angulation). The following parameters were set: radial articular angle and carpal slip prior to and after angulation correction, the healing period, the range of movement of the surrounding joints and occurrence of complications.

Results: We recorded only one case of delayed healing which was subsequently sustained by autospongioplastics and adjusted to normal. In the rest of the cases deformity correction occurred and the defined parameters were then corrected to normal. We observed no postoperative complications or permanent consequences.

Conclusions: A two-year follow-up period monitoring treatment and therapeutic results of deformities in the forearm bones at our clinic, confirmed a minimal incidence of complications and a high percentage of successfully treated cases.

\section{INTRODUCTION}

The locking compression plate (LCP) is frequently applied in adult traumatology for surgical treatment of fractures. Its use in pediatric traumatology is very limited. The system is based on a stable connection between the plate and the screw due to the threaded screw head and the threaded plate hole. The plate holes, determining the direction of screw insertion, are combination holes that allow placement of conventional compression screws (Fig. 1). Osteosynthesis with LCP is thus a lot more stable and compact, constituting an internal fixator ${ }^{1}$.

The use of LCP in acute pediatric traumatology is not advantageous. However, stable fixation with the locking compression plate seemed to be very favourable for a different traumatologic-orthopaedic condition in this age group. In some cases of inadequate fracture healing the correction of posttraumatic deformity is required and next to the standard use of an external fixator, osteosynthesis with LCP is another option in fragment fixation. Its use in children is not limited to posttraumatic deformities. It can be applied also in the correction of no posttraumatic deformities.

The angular deformities of distal forearm ( congenital or acquired ) are treated to achievement the correct length and axis of the forearm bones ${ }^{2}$. In some cases we can use an external fixator. Compared to an external fixator, LCP is more advantageous, especially in cases where fixation is preceded by correction osteotomy and a major surgical procedure is thus necessary ${ }^{1}$

In our prospective study we analysed therapeutic results of correction osteotomies with fixation by means of the LCP system performed at our clinic between 2006 and 2007. External fixation had previously been preferred in correction osteotomy. In addition to the results of our therapy, we focused on the incidence of postoperative complications and permanent consequences.

\section{MATERIALS AND METHODS}

Our source data was collected prospectively from the records of patients where LCP was used for angulation correction between 2006 and 2007. The patients were divided by sex, the age range was defined and two groups were formed based on the initial diagnosis: patients with posttraumatic deformities and patients with congenital deformities. The next step included monitoring of the defined parameters in each group, i.e. RAA (radial articular angle: the angle between a line drawn perpendicular to the long axis of the radius and another line that passes through the articular surface; normally between $15^{\circ}$ and $30^{\circ}$ ) and CS (carpal slip: in AP projection it is the percentage of the lunate on the ulnar side of a line drawn 
from the ulnar borders of the distal and proximal radial physeal plates; normally less than $50 \%$ ) prior to and after angulation correction, the healing period, the range of movement of the surrounding joints and occurrence of complications. All patients were invited for first X-ray examination after 3 weeks and then again after 3 weeks. After this period, every 3 months the control X-ray examination was performed, until the plate was removed.

Between 2006 and 2007 surgical correction of angulation in the forearm bones with LCP was performed in 7 patients at the Clinic of Pediatric Surgery, Orthopaedics and Traumatology, the Faculty Hospital Brno. There were 4 boys ( $57 \%$ ) and 3 girls ( $43 \%$ ) between 10 and 18 years of age. The average age at the time of surgery was 14 years (see Table 1).

Our set of patients was divided based on their initial diagnosis: patients with a posttraumatic deformity, i.e. a pseudo-Madelung deformity ( 2 patients, $29 \%$ ), and patients with a non-traumatic deformity ( 5 patients, $71 \%$; 3 of them with congenital shortening of ulna, valgus deformity and overgrowth of radius and 2 patients with exostoses multiplices with shortening of ulna and overgrowth of radius with ulnar angulation). Subsequent evaluation of the treatment and therapeutic results was carried out individually for each group.

\section{RESULTS}

In the group of patients with a posttraumatic deformity, RAA ranged between $4^{\circ}$ and $6^{\circ}$, the mean was $5^{\circ}$. Following angulation correction, we observed correction of the values to normal $\left(15^{\circ}-30^{\circ}\right)$ in all cases. CS was normal (less than $50 \%$ ) in all cases prior to angulation correction (Table 1).

In the group of patients with a congenital deformity, also in patients with exostoses multiplices, RAA ranged between $33^{\circ}$ and $60^{\circ}$ (the mean was $44^{\circ}$ ) prior to angulation correction. All patients exhibited normal values after angulation correction. In patients with a congenital deformity, CS was normal prior to angulation correction. In patients with exostoses multiplices, CS was $70 \%$. After

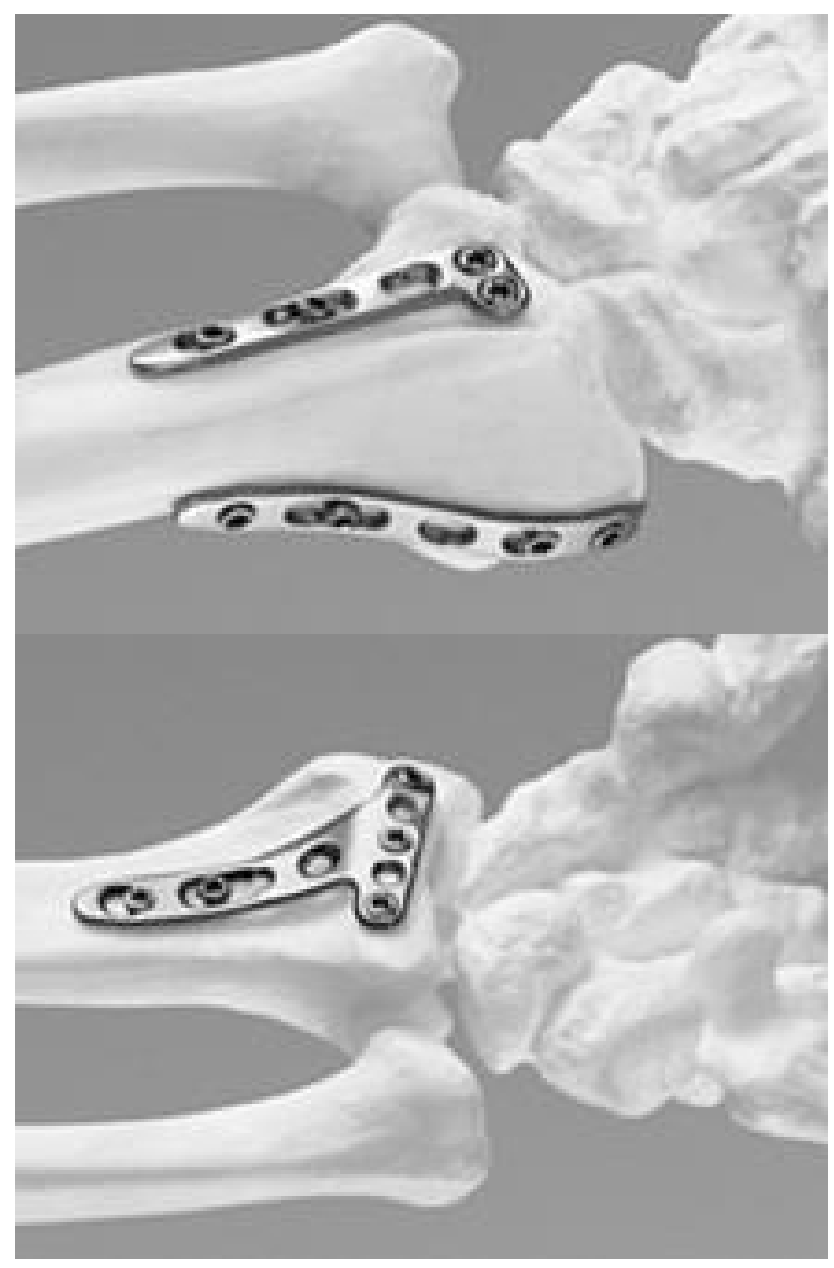

Fig. 1. LCP distal radius plates (Lcp technique guide, 2003, Synthes (USA)).

correction with LCP, CS values were adjusted to normal in all cases (Table 1). Example of healing - patient No.4 (Figs. 2, 3, 4).

In both groups, the physiological finding was in the elbow joint. The clinical finding prior to angulation correction was dominated by forearm shortening, distal forearm deviation and restricted movement of the radio-

Table 1. Summary of observed patients with LCP.

\begin{tabular}{|c|c|c|l|c|c|c|}
\hline Patient No. & Sex (M/F) & Age* & Deformity type & $\begin{array}{c}\text { RAA } \\
\text { (before/after) } \\
\left({ }^{\circ}\right)\end{array}$ & $\begin{array}{c}\text { SC } \\
\text { (before/after) } \\
(\%)\end{array}$ & $\begin{array}{c}\text { Average healing } \\
\text { period }\end{array}$ \\
\hline 1 & M & 14 & posttraumatic & $4 / 20$ & $40 / 40$ & 6 weeks \\
\hline 2 & F & 18 & posttraumatic & $6 / 18$ & $45 / 45$ & 7 weeks \\
\hline 3 & M & 12 & congenital & $33 / 25$ & $45 / 45$ & 5 weeks \\
\hline 4 & M & 10 & congenital & $40 / 21$ & $38 / 38$ & 6 weeks \\
\hline 5 & F & 15 & congenital & $60 / 28$ & $42 / 42$ & $* *$ \\
\hline 6 & F & 16 & exostosis & $42 / 19$ & $70 / 45$ & 6 weeks \\
\hline 7 & M & 13 & exostosis & $45 / 22$ & $70 / 42$ & 6 weeks \\
\hline
\end{tabular}

* at the time of surgery

** technical error in LCP application; 5 months after correction autospongioplastics was used/ subsequently normal 


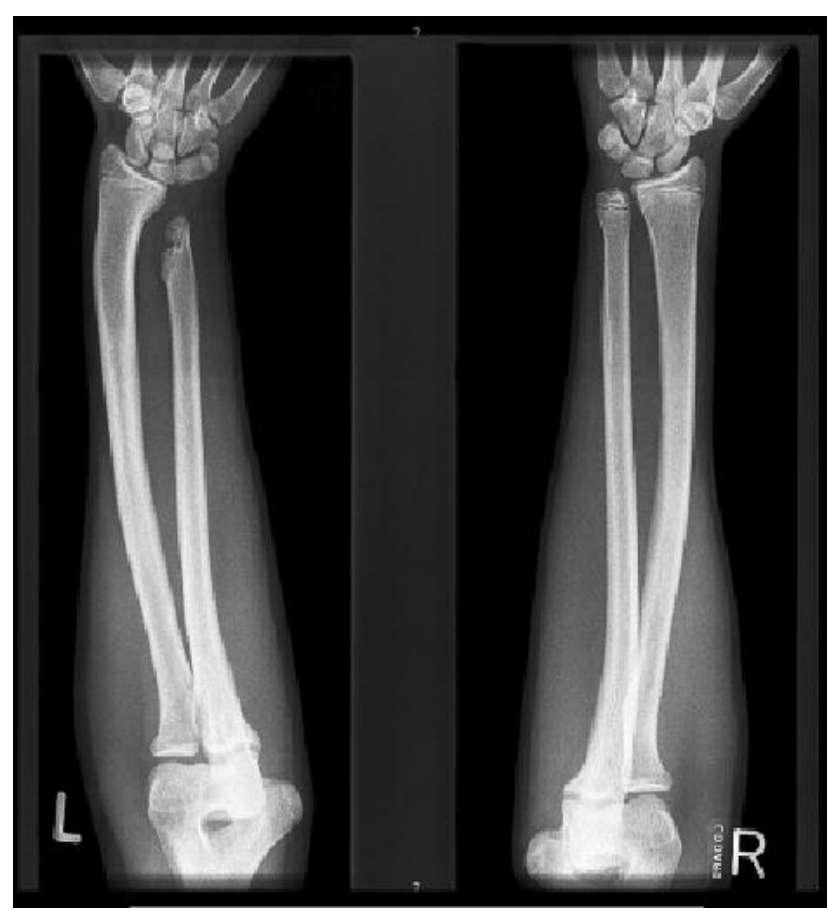

Fig. 2. Left distal radius deformity before corrective osteotomy compared with normal right radius.

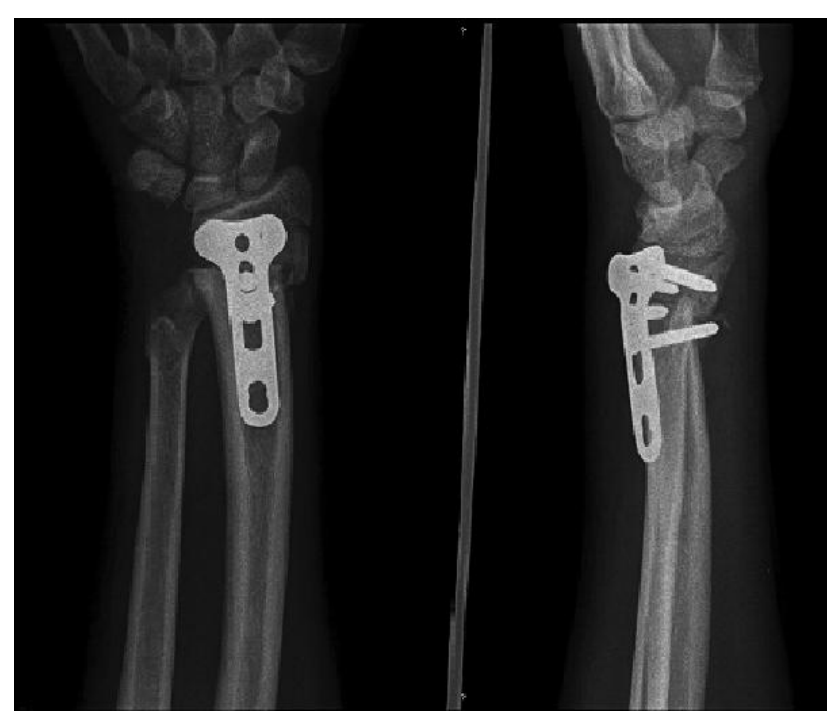

Fig. 3. Left distal radius after osteotomy and LCP application in the course of healing.

carpal joint, mainly radial duction. All patients exhibited insignificant ulnar shortening without the necessity of lengthening.

The average healing period within the whole set of patients was 6 weeks. In one case (14\%), the eldest patient, we observed delayed healing due to a technical error during LCP application which was sustained by autospongioplastics and subsequently adjusted to normal (see Table 1). The movement of the wrist after a longer period from the surgery is normal, in 3 cases ( $43 \%$ ) full radial duction is still delayed and the patients are included in a rehabilitation programme.

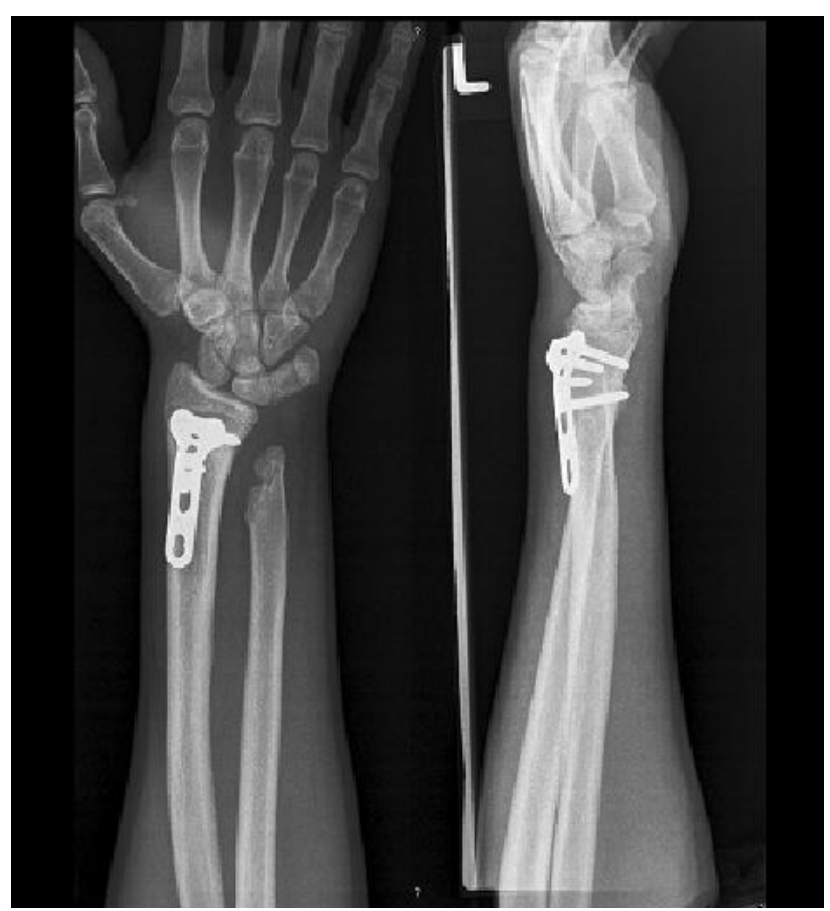

Fig. 4. Left distal radius after healing and before LCP extraction.

\section{DISCUSSION}

Primary indication for LCP in pediatric fractures is very rare. An extensive surgical procedure that is required is its major disadvantage. However, we use LCP for fixation after correction osteotomy and benefit from its high stability, better comfort for patients, early mobilization of the affected limb, support of formation and growth of the callus and quicker defect healing. The fact that the plates do not have to be placed on the bone surface is another advantage of the LCP system. Periosteum incision is not required and the blood supply of periosteum is thus preserved. They are referred to as internal fixators.

Anatomic differences in the ends of individual bones are reflected and in addition to universal LCP, special plates are available to be used for different bone types (e.g. proximal and distal humerus, distal radius, distal femur, proximal and distal tibia etc.). In adult traumatology LCP is used particularly for intra-articular fractures involving the metaphysis and also traversing the diaphysis of the bone. They are frequently applied in distal radial fractures ${ }^{1,3,4}$

The distal end of both forearm bones is known for its capability of remodeling depending on the age of patient at the time of injury and also on the distance of the fracture line from the physeal fissure ${ }^{5}$. The method of choice for the treatment of traumatic deformities in the distal forearm in children is accurate closed reduction and plaster fixation, possibly also the selection of suitable osteosynthetic material and a mini-invasive procedure for its insertion. This is commonly achieved by Kirschner wires. These methods of mini-invasive osteosynthesis are usually associated with successful fracture healing ${ }^{3,6}$

Compared to an external fixator, LCP is more advantageous, especially in cases where fixation is preceded by 
correction osteotomy and a major surgical procedure is thus necessary ${ }^{1,7,8,9}$

Although therapeutic standards at different clinics may vary, with proper therapy the percentage of complications in deformity correction with LCP is minimal. This proved to be true not only in our study but also in foreign scholarly literature ${ }^{1,4,9}$.

\section{CONCLUSION}

A two-year follow-up period monitoring treatment and therapeutic results of deformities in the distal forearm bones at our clinic, confirmed a minimal incidence of complications and a high percentage of successfully treated cases.

\section{REFERENCES}

1. Ruedi TP, Buckley RE, Moran ChG. AO Principles of Fracture Managment (volume 1,2), AO Publishing, Switzerland, Davoz, 2000 .

2. Tachdjian MO. Pediatric Orthopedics. Vol I-IV. Philadelphia: W.B.Saunders, 2003.

3. Rockwood ChA, Wilkins KE, King RE. Fractures in children, Vol. 3, J.B. Lippincott Company, Philadelphia, 1984.

4. Benson MKD, Fixsen JA, Macnicol MF, Parsch K. Children's orthopaedics and Fractures, (second edition). Harcourt Publichers Limited, 2002.

5. Plánka L, Chalupová P, Škvařil J, Poul J, Gál P. Schopnost remodelace distálního radia při hojení zlomenin v dětském věku, Rozhl Chir. 2005; 84(10):505-10.

6. Šnajdauf J, Cvachovec K, Trč T. Dětská traumatologie, (1. vydání). Praha 2002.

7. Dungl P. Ortopedie. (1. vydání). Praha, GRADA, 2005.

8. Okáč I, Poul J,Vytopil M. Deformity předloktí způsobené benigními kostními nádory, léčení zevním fixátorem. Acta Chirurg Ortop et Traumatolog Čechoslovaca 1996; 63:214-220.

9. Justan I, Poul J, Gál P, Bibrová Š.Korekce postraumatických délkových diskrepancí předloktetních kostí u dětí. Acta Chirurg Ortop et Traumatolog Čechoslovaca 2004; 71:373-378. 